\title{
Coupled fixed point theorems for mixed $g$-monotone mappings in partially ordered metric spaces
}

Duran Turkoglu1,2 and Muzeyyen Sangurlu1,3*

\section{*Correspondence:}

msangurlu@gazi.edu.tr

'Department of Mathematics,

Faculty of Science, University of

Gazi, Teknikokullar, Ankara, 06500,

Turkey

${ }^{3}$ Department of Mathematics,

Faculty of Science and Arts,

University of Giresun, Gazipaşa, Giresun, Turkey

Full list of author information is available at the end of the article

\begin{abstract}
In this paper, we prove some coupled coincidence point results for mixed $g$-monotone mappings in partially ordered metric spaces. The main results of this paper are generalizations of the main results of Luong and Thuan (Nonlinear Anal. 74:983-992, 2011).

MSC: Primary 54H25; secondary $47 \mathrm{H} 10$

Keywords: coupled fixed point; mappings having a mixed monotone property; partially ordered metric space
\end{abstract}

\section{Introduction and preliminaries}

Fixed point theory plays a major role in mathematics. The Banach contraction principle [1] is the simplest one corresponding to fixed point theory. So a large number of mathematicians have extended it and have been interested in fixed point theory in some metric spaces. One of these spaces is a partially ordered metric space, that is, metric spaces endowed with a partial ordering. The first result in this direction was given by Ran and Reurings [2] who presented their applications to a matrix equation. Subsequently, the existence of solutions for matrix equations or ordinary differential equations by applying fixed point theorems were presented in [2-7].

The existence of a fixed point for contraction type mappings in partially ordered metric spaces has been considered by Ran and Reurings [2], Bhaskar and Lakshmikantham [4], Nieto and Rodriquez-Lopez [6, 7], Lakshmikantham and Ćirić [8], Agarwal et al. [9] and Samet [10]. Bhaskar and Lakshmikantham [4] introduced the notion of coupled fixed point and proved some coupled fixed point theorems for mappings satisfying the mixed monotone property and discussed the existence and uniqueness of a solution for a periodic boundary value problem. Lakshmikantham and Ćirić [8] introduced the concept of a mixed $g$-monotone mapping and proved coupled coincidence and common fixed point theorems that extend theorems from [4]. Subsequently, many authors obtained several coupled coincidence and coupled fixed point theorems in some ordered metric spaces [11-27].

Definition 1 ([4]) Let $(X, \leq)$ be a partially ordered set and $F: X \times X \rightarrow X$. The mapping $F$ is said to have the mixed monotone property if $F(x, y)$ is monotone non-decreasing in $x$ 
and is monotone non-decreasing in $y$, that is, for any $x, y \in X$,

$$
x_{1}, x_{2} \in X, \quad x_{1} \leq x_{2} \quad \Longrightarrow \quad F\left(x_{1}, y\right) \leq F\left(x_{2}, y\right)
$$

and

$$
y_{1}, y_{2} \in X, \quad y_{1} \leq y_{2} \quad \Longrightarrow \quad F\left(x, y_{1}\right) \geq F\left(x, y_{2}\right) .
$$

Definition 2 ([4]) An element $(x, y) \in X \times X$ is called a coupled fixed point of the mapping $F: X \times X \rightarrow X$ if $F(x, y)=x, F(y, x)=y$.

Definition 3 ([8]) An element $(x, y) \in X \times X$ is called a coupled coincidence point of mappings $F: X \times X \rightarrow X$ and $g: X \rightarrow X$ if $F(x, y)=g x, F(y, x)=g y$.

Definition 4 ([8]) Let $X$ be non-empty set and $F: X \times X \rightarrow X$ and $g: X \rightarrow X$. We say $F$ and $g$ are commutative if $g F(x, y)=F(g x, g y)$ for all $x, y \in X$.

Definition 5 ([8]) Let $(X, \leq)$ be a partially ordered set and $F: X \times X \rightarrow X, g: X \rightarrow X$ be mappings. The mapping $F$ is said to have the mixed $g$-monotone property if $F$ is monotone $g$-non-decreasing in its first argument and is monotone $g$-non-increasing in the second argument, that is, for any $x, y \in X$,

$$
x_{1}, x_{2} \in X, \quad g x_{1} \leq g x_{2} \quad \Longrightarrow \quad F\left(x_{1}, y\right) \leq F\left(x_{2}, y\right)
$$

and

$$
y_{1}, y_{2} \in X, \quad g y_{1} \leq g y_{2} \quad \Longrightarrow \quad F\left(x, y_{1}\right) \geq F\left(x, y_{2}\right) .
$$

Lemma 1 ([28]) Let $X$ be a non-empty set and $F: X \times X \rightarrow X$ and $g: X \rightarrow X$ be mappings. Then there exists a subset $E \subseteq X$ such that $g(E)=g(X)$ and $g: E \rightarrow X$ is one-to-one.

Theorem 1 ([4]) Let $(X, \leq)$ be a partially ordered set and suppose that there exists a metric $d$ on $X$ such that $(X, d)$ is a complete metric space. Let $F: X \times X \rightarrow X$ be a continuous mapping having the mixed monotone property on $X$. Assume that there exists $k \in[0,1)$ with

$$
d(F(x, y), F(u, v)) \leq \frac{k}{2}[d(x, u)+d(y, v)] \text { for all } x \geq u \text { and } y \leq v .
$$

If there exist two elements $x_{0}, y_{0} \in X$ with

$$
x_{0} \leq F\left(x_{0}, y_{0}\right) \quad \text { and } \quad y_{0} \geq F\left(y_{0}, x_{0}\right) \text {, }
$$

then there exist $x, y \in X$ such that

$$
x=F(x, y) \text { and } y=F(y, x) .
$$

Theorem $2([4])$ Let $(X, \leq)$ be a partially ordered set and suppose that there exists a metric $d$ on $X$ such that $(X, d)$ is a complete metric space. Assume that $X$ has the following property: 
(1) if a non-decreasing sequence $\left\{x_{n}\right\} \rightarrow x$, then $x_{n} \leq x$ for all $n \in \mathbb{N}$,

(2) if a non-increasing sequence $\left\{y_{n}\right\} \rightarrow y$, then $y \leq y_{n}$ for all $n \in \mathbb{N}$.

Let $F: X \times X \rightarrow X$ be a mapping having the mixed monotone property on $X$. Assume that there exists $k \in[0,1)$ with

$$
d(F(x, y), F(u, v)) \leq \frac{k}{2}[d(x, u)+d(y, v)] \text { for all } x \geq u \text { and } y \leq v .
$$

If there exist two elements $x_{0}, y_{0} \in X$ with

$$
x_{0} \leq F\left(x_{0}, y_{0}\right) \text { and } y_{0} \geq F\left(y_{0}, x_{0}\right) \text {, }
$$

then there exist $x, y \in X$ such that

$$
x=F(x, y) \text { and } y=F(y, x) .
$$

Theorem 3 ([29]) Let $(X, \leq)$ be a partially ordered set and suppose that there exists a metric $d$ on $X$ such that $(X, d)$ is a complete metric space. Let $(X, \leq)$ be a partially ordered set and suppose that there exists a metric $d$ on $X$ such that $(X, d)$ is a complete metric space. Let $F: X \times X \rightarrow X$ be a mapping having the mixed monotone property on $X$ and there exist two elements $x_{0}, y_{0} \in X$ with $x_{0} \leq F\left(x_{0}, y_{0}\right)$ and $y_{0} \geq F\left(y_{0}, x_{0}\right)$. Suppose that $F, g$ satisfy

$$
\varphi(d(F(x, y), F(u, v))) \leq \frac{1}{2} \varphi(d(x, u)+d(y, v))-\psi\left(\frac{d(x, u)+d(y, v)}{2}\right)
$$

for all $x, y, u, v \in X$ with $x \geq u$ and $y \leq v$. Suppose that either

(1) $F$ is continuous or

(2) $X$ has the following property:

(a) if a non-decreasing sequence $\left\{x_{n}\right\} \rightarrow x$, then $x_{n} \leq x$ for all $n \in \mathbb{N}$,

(b) if a non-increasing sequence $\left\{y_{n}\right\} \rightarrow y$, then $y \leq y_{n}$ for all $n \in \mathbb{N}$.

Then there exist $x, y \in X$ such that

$$
x=F(x, y) \text { and } y=F(y, x) \text {, }
$$

that is, $F$ has a coupled fixed point in $X$.

\section{The main results}

In this paper, we prove coupled coincidence and common fixed point theorems for mixed $g$-monotone mappings satisfying more general contractive conditions in partially ordered metric spaces. We also present results on existence and uniqueness of coupled common fixed points. Our results improve those of Luong and Thuan [29]. Our work generalizes, extends and unifies several well known comparable results in the literature.

Let $\Phi$ denote all functions $\varphi:[0, \infty) \rightarrow[0, \infty)$ which satisfy

(1) $\varphi$ is continuous and non-decreasing,

(2) $\varphi(t)=0$ and only if $t=0$,

(3) $\varphi(t+s) \leq \varphi(t)+\varphi(s), \forall t, s \in[0, \infty)$

and $\Psi$ denote all functions $\psi:[0, \infty) \rightarrow[0, \infty)$ which satisfy $\lim _{t \rightarrow r} \psi(t)>0$ for all $r>0$ and $\lim _{t \rightarrow 0^{+}} \psi(t)=0$. 
Theorem 4 Let $(X, \leq)$ be a partially ordered set and suppose that there exists a metric d on $X$ such that $(X, d)$ is a complete metric space. Let $(X, \leq)$ be a partially ordered set and suppose that there exists a metric $d$ on $X$ such that $(X, d)$ is a complete metric space. Let $F: X \times X \rightarrow X$ be a mapping having the mixed monotone property on $X$ and there exist two elements $x_{0}, y_{0} \in X$ with $x_{0} \leq F\left(x_{0}, y_{0}\right)$ and $y_{0} \geq F\left(y_{0}, x_{0}\right)$. Suppose that $F, g$ satisfy

$$
\varphi(d(F(x, y), F(u, v))) \leq \frac{1}{2} \varphi(d(g x, g u)+d(g y, g v))-\psi\left(\frac{d(g x, g u)+d(g y, g v)}{2}\right)
$$

for all $x, y, u, v \in X$ with $g x \leq g u$ and $g y \geq g \nu, F(X \times X) \subseteq g(X), g(X)$ is complete and $g$ is continuous.

Suppose that either

(1) $F$ is continuous or

(2) $X$ has the following property:

(a) if a non-decreasing sequence $\left\{x_{n}\right\} \rightarrow x$, then $x_{n} \leq x$ for all $n \in \mathbb{N}$,

(b) if a non-increasing sequence $\left\{y_{n}\right\} \rightarrow y$, then $y \leq y_{n}$ for all $n \in \mathbb{N}$.

Then there exist $x, y \in X$ such that

$$
g x=F(x, y) \text { and } g y=F(y, x) \text {, }
$$

that is, $F$ and $g$ have a coupled coincidence point in $X \times X$.

Proof Using Lemma 1, there exists $E \subseteq X$ such that $g(E)=g(X)$ and $g: E \rightarrow X$ is one-toone. We define a mapping $A: g(E) \times g(E) \rightarrow X$ by

$$
A(g x, g y)=F(x, y), \quad \forall g x, g y \in g(E) .
$$

As $g$ is one-to-one on $g(E)$, so $A$ is well defined. Thus, it follows from (2.1) and (2.2) that

$$
\varphi(A(x, y), A(u, v)) \leq \frac{1}{2} \varphi(d(g x, g u)+d(g y, g v))-\psi\left(\frac{d(g x, g u)+d(g y, g v)}{2}\right)
$$

for all $g x, g y, g u, g v \in g(E)$ with $g x \leq g u$ and $g y \geq g \nu$. Since $F$ has the mixed $g$-monotone property, for all $x, y \in X$, we have

$$
x_{1}, x_{2} \in X, \quad g x_{1} \leq g x_{2} \quad \Longrightarrow \quad F\left(x_{1}, y\right) \leq F\left(x_{2}, y\right)
$$

and

$$
y_{1}, y_{2} \in X, \quad g y_{1} \geq g y_{2} \quad \Longrightarrow \quad F\left(x, y_{1}\right) \leq F\left(x, y_{2}\right) .
$$

Thus, it follows from (2.2), (2.4) and (2.5) that, for all $g x, g y \in g(E)$,

$$
g x_{1}, g x_{2} \in g(X), \quad g x_{1} \leq g x_{2} \quad \Longrightarrow \quad A\left(g x_{1}, g y\right) \leq A\left(g x_{2}, g y\right)
$$

and

$$
g y_{1}, g y_{2} \in g(X), \quad g y_{1} \geq g y_{2} \quad \Longrightarrow \quad A\left(g x, g y_{1}\right) \leq A\left(g x, g y_{2}\right),
$$

which implies that $A$ has the mixed monotone property. 
Suppose that assumption (1) holds. Since $F$ is continuous, $A$ is also continuous. Using Theorem 3 with the mapping $A$, it follows that $A$ has a coupled fixed point $(u, v) \in g(E) \times$ $g(E)$.

Suppose that assumption (2) holds. We can conclude similarly in the proof of Theorem 3 that the mapping $A$ has a coupled fixed point $(u, v) \in g(X) \times g(X)$.

Finally, we prove that $F$ and $g$ have a coupled fixed point in $X$. Since $(u, v)$ is a coupled fixed point of $A$, we get

$$
u=A(u, v), \quad v=A(v, u)
$$

Since $(u, v) \in g(X) \times g(X)$, there exists a point $\left(u^{\prime}, v^{\prime}\right) \in X \times X$ such that

$$
u=g u^{\prime}, \quad v=g v^{\prime} .
$$

Thus, it follows from (2.6) and (2.7) that

$$
g u^{\prime}=A\left(g u^{\prime}, g v^{\prime}\right), \quad g v^{\prime}=A\left(g v^{\prime}, g u^{\prime}\right) .
$$

Also, from (2.2) and (2.8), we get

$$
g u^{\prime}=F\left(u^{\prime}, v^{\prime}\right), \quad g v^{\prime}=F\left(v^{\prime}, u^{\prime}\right) .
$$

Therefore, $\left(u^{\prime}, v^{\prime}\right)$ is a coupled coincidence point of $F$ and $g$. This completes the proof.

Corollary 1 Let $(X, \leq)$ be a partially ordered set and suppose that there exists a metric $d$ on $X$ such that $(X, d)$ is a complete metric space. Let $(X, \leq)$ be a partially ordered set and suppose that there exists a metric $d$ on $X$ such that $(X, d)$ is a complete metric space. Let $F: X \times X \rightarrow X$ be a mapping having the mixed monotone property on $X$ and there exist two elements $x_{0}, y_{0} \in X$ with $x_{0} \leq F\left(x_{0}, y_{0}\right)$ and $y_{0} \geq F\left(y_{0}, x_{0}\right)$. Suppose that $F, g$ satisfy

$$
\varphi(d(F(x, y), F(u, v))) \leq \frac{k}{2} d(g x, g u)+d(g y, g v)
$$

for all $x, y, u, v \in X$ with $g x \leq g u$ and $g y \geq g v, F(X \times X) \subseteq g(X), g(X)$ is complete and $g$ is continuous.

Suppose that either

(1) $F$ is continuous or

(2) $X$ has the following property:

(a) if a non-decreasing sequence $\left\{x_{n}\right\} \rightarrow x$, then $x_{n} \leq x$ for all $n \in \mathbb{N}$,

(b) if a non-increasing sequence $\left\{y_{n}\right\} \rightarrow y$, then $y \leq y_{n}$ for all $n \in \mathbb{N}$.

Then there exist $x, y \in X$ such that

$$
g x=F(x, y) \text { and } g y=F(y, x) \text {, }
$$

that is, $F$ and $g$ have a coupled coincidence point in $X \times X$.

Proof In Theorem 4, taking $\varphi(t)=t$, we get Corollary 1 . 
Corollary 2 Let $(X, \leq)$ be a partially ordered set and suppose that there exists a metric $d$ on $X$ such that $(X, d)$ is a complete metric space. Let $(X, \leq)$ be a partially ordered set and suppose that there exists a metric $d$ on $X$ such that $(X, d)$ is a complete metric space. Let $F: X \times X \rightarrow X$ be a mapping having the mixed monotone property on $X$, and there exist two elements $x_{0}, y_{0} \in X$ with $x_{0} \leq F\left(x_{0}, y_{0}\right)$ and $y_{0} \geq F\left(y_{0}, x_{0}\right)$. Suppose that $F, g$ satisfy

$$
d(F(x, y), F(u, v)) \leq \frac{1}{2}(d(g x, g u)+d(g y, g v))-\psi\left(\frac{d(g x, g u)+d(g y, g v)}{2}\right)
$$

for all $x, y, u, v \in X$ with $g x \leq g u$ and $g y \geq g v, F(X \times X) \subseteq g(X), g(X)$ is complete and $g$ is continuous.

Suppose that either

(1) $F$ is continuous or

(2) $X$ has the following property:

(a) if a non-decreasing sequence $\left\{x_{n}\right\} \rightarrow x$, then $x_{n} \leq x$ for all $n \in \mathbb{N}$,

(b) if a non-increasing sequence $\left\{y_{n}\right\} \rightarrow y$, then $y \leq y_{n}$ for all $n \in \mathbb{N}$.

Then there exist $x, y \in X$ such that

$$
g x=F(x, y) \text { and } g y=F(y, x) \text {, }
$$

that is, $F$ and $g$ have a coupled coincidence point in $X \times X$.

Proof In Corollary 1, taking $\psi(t)=\frac{1-k}{2} t$, we get Corollary 2 .

Theorem 5 Let $(X, \leq)$ be a partially ordered set and suppose that there exists a metric $d$ on $X$ such that $(X, d)$ is a complete metric space. Let $(X, \leq)$ be a partially ordered set and suppose that there exists a metric $d$ on $X$ such that $(X, d)$ is a complete metric space. Let $F: X \times X \rightarrow X$ be a mapping having the mixed monotone property on $X$ and there exist two elements $x_{0}, y_{0} \in X$ with $x_{0} \leq F\left(x_{0}, y_{0}\right)$ and $y_{0} \geq F\left(y_{0}, x_{0}\right)$. Suppose that $F, g$ satisfy

$$
\varphi(d(F(x, y), F(u, v))) \leq \frac{1}{2} \varphi(d(g x, g u)+d(g y, g v))-\psi\left(\frac{d(g x, g u)+d(g y, g v)}{2}\right)
$$

for all $x, y, u, v \in X$ with $g x \leq g u$ and $g y \geq g v, F(X \times X) \subseteq g(X), g(X)$ is complete and $g$ is continuous.

Suppose that either

(1) $F$ is continuous or

(2) $X$ has the following property:

(a) if a non-decreasing sequence $\left\{x_{n}\right\} \rightarrow x$, then $x_{n} \leq x$ for all $n \in \mathbb{N}$,

(b) if a non-increasing sequence $\left\{y_{n}\right\} \rightarrow y$, then $y \leq y_{n}$ for all $n \in \mathbb{N}$.

Then there exist $x, y \in X$ such that

$$
g x=F(x, y), \quad g y=F(y, x)
$$

and

$$
x=g x=F(x, y), \quad y=g y=F(y, x),
$$

that is, $F$ and $g$ have a coupled common fixed point $(x, y) \in X \times X$. 
Proof Following the proof of Theorem 4, $F$ and $g$ have a coupled coincidence point. We only have to show that $x=g x$ and $y=g y$.

Now, $x_{0}$ and $y_{0}$ are two points in the statement of Theorem 4. Since $F(X \times X) \subseteq g(X)$, we can choose $x_{1}, y_{1} \in X$ such that $g x_{1}=F\left(x_{0}, y_{0}\right)$ and $g y_{1}=F\left(y_{0}, x_{0}\right)$. In the same way, we construct $g x_{2}=F\left(x_{1}, y_{1}\right)$ and $g y_{2}=F\left(y_{1}, x_{1}\right)$. Continuing in this way, we can construct two sequences $\left\{x_{n}\right\}$ and $\left\{y_{n}\right\}$ in $X$ such that

$$
g x_{n+1}=F\left(x_{n}, y_{n}\right) \quad \text { and } \quad g y_{n+1}=F\left(y_{n}, x_{n}\right), \quad \forall n \geq 0 .
$$

Since $g x \geq g x_{n+1}$ and $g y \leq g y_{n+1}$, from (2.1) and (2.9), we have

$$
\begin{aligned}
\varphi\left(d\left(g x_{n+1}, g x\right)\right) & =\varphi\left(d\left(F\left(x_{n}, y_{n}\right), F(x, y)\right)\right) \\
& \leq \frac{1}{2} \varphi\left(d\left(g x_{n}, g x\right)+d\left(g y_{n}, g y\right)\right)-\psi\left(\frac{d\left(g x_{n}, g x\right)+d\left(g y_{n}, g y\right)}{2}\right) .
\end{aligned}
$$

Similarly, since $g y_{n+1} \geq g y$ and $g x_{n+1} \leq g x$, from (2.1) and (2.9), we have

$$
\begin{aligned}
\varphi\left(d\left(g y, g y_{n+1}\right)\right) & =\varphi\left(d\left(F(y, x), F\left(y_{n}, x_{n}\right)\right)\right) \\
& \leq \frac{1}{2} \varphi\left(d\left(g y, g y_{n}\right)+d\left(g x, g x_{n}\right)\right)-\psi\left(\frac{d\left(g y, g y_{n}\right)+d\left(g x, g x_{n}\right)}{2}\right) .
\end{aligned}
$$

From (2.10) and (2.11), we have

$$
\begin{aligned}
& \varphi\left(d\left(g x_{n+1}, g x\right)\right)+\varphi\left(d\left(g y, g y_{n+1}\right)\right) \\
& \quad \leq \varphi\left(d\left(g x_{n}, g x\right)+d\left(g y_{n}, g y\right)\right)-2 \psi\left(\frac{d\left(g x_{n}, g x\right)+d\left(g y_{n}, g y\right)}{2}\right) .
\end{aligned}
$$

By property (3) of $\varphi$, we have

$$
\varphi\left(d\left(g x_{n+1}, g x\right)+d\left(g y, g y_{n+1}\right)\right) \leq \varphi\left(d\left(g x_{n+1}, g x\right)\right)+\varphi\left(d\left(g y, g y_{n+1}\right)\right) .
$$

From (2.12) and (2.13), we have

$$
\varphi\left(d\left(g x_{n+1}, g x\right)+d\left(g y, g y_{n+1}\right)\right) \leq \varphi\left(d\left(g x_{n}, g x\right)+d\left(g y_{n}, g y\right)\right)-2 \psi\left(\frac{d\left(g x_{n}, g x\right)+d\left(g y_{n}, g y\right)}{2}\right),
$$

which implies

$$
\varphi\left(d\left(g x_{n+1}, g x\right)+d\left(g y, g y_{n+1}\right)\right) \leq \varphi\left(d\left(g x_{n}, g x\right)+d\left(g y_{n}, g y\right)\right) .
$$

Using the fact that $\varphi$ is non-decreasing, we get

$$
d\left(g x_{n+1}, g x\right)+d\left(g y, g y_{n+1}\right) \leq d\left(g x_{n}, g x\right)+d\left(g y_{n}, g y\right) .
$$

Set $\delta_{n}=d\left(g x_{n+1}, g x\right)+d\left(g y_{n+1}, g y\right)$, then sequence $\left\{\delta_{n}\right\}$ is decreasing. Therefore, there is some $\delta \geq 0$ such that

$$
\lim _{n \rightarrow \infty} \delta_{n}=\lim _{n \rightarrow \infty}\left[d\left(g x_{n+1}, g x\right)+d\left(g y_{n+1}, g y\right)\right]=\delta .
$$


We shall show that $\delta=0$. Suppose, to the contrary, that $\delta>0$. Then taking the limit as $n \rightarrow \infty$ (equivalently, $\delta_{n} \rightarrow \delta$ ) of both sides of (2.13) and having in mind that we suppose that $\lim _{t \rightarrow r} \psi(t)>0$ for all $r>0$ and $\varphi$ is continuous, we have

$$
\varphi(\delta)=\lim _{n \rightarrow \infty} \varphi\left(\delta_{n}\right) \leq \lim _{n \rightarrow \infty}\left[\varphi\left(\delta_{n-1}\right)-2 \psi\left(\frac{\delta_{n-1}}{2}\right)\right]=\varphi(\delta)-2 \lim _{\delta_{n-1} \rightarrow \delta} \psi\left(\frac{\delta_{n-1}}{2}\right)<\varphi(\delta),
$$

a contradiction. Thus $\delta=0$, that is,

$$
\lim _{n \rightarrow \infty} \delta_{n}=\lim _{n \rightarrow \infty}\left[d\left(g x_{n+1}, g x\right)+d\left(g y_{n+1}, g y\right)\right]=0 .
$$

Hence $d\left(g x_{n+1}, g x\right)=0$ and $d\left(g y_{n+1}, g y\right)=0$, that is, $x=g x$ and $y=g y$.

Theorem 6 In addition to the hypotheses of Theorem 4, suppose that for every $(x, y),(z, t)$ in $X \times X$, there exists $(u, v)$ in $X \times X$ that is comparable to $(x, y)$ and $(z, t)$, then $F$ and $g$ have a unique coupled fixed point.

Proof From Theorem 4, the set of coupled fixed points of $F$ is non-empty. Suppose that $(x, y)$ and $(z, t)$ are coupled coincidence points of $F$, that is, $g x=F(x, y), g y=F(y, x), g z=$ $F(z, t)$ and $g t=F(t, z)$. We will prove that

$$
g x=g z \text { and } \quad g y=g t .
$$

By assumption, there exists $(u, v)$ in $X \times X$ such that $(F(u, v), F(v, u))$ is comparable with $(F(x, y), F(y, x))$ and $(F(z, t), F(t, z))$. Put $u_{0}=u$ and $v_{0}=v$ and choose $u_{1}, v_{1} \in X$ so that $g u_{1}=F\left(u_{0}, v_{0}\right)$ and $g v_{1}=F\left(v_{0}, u_{0}\right)$. Then, similarly as in the proof of Theorem 3, we can inductively define sequences $\left\{g u_{n}\right\},\left\{g v_{n}\right\}$ with

$$
g u_{n+1}=F\left(u_{n}, v_{n}\right) \quad \text { and } g v_{n+1}=F\left(v_{n}, u_{n}\right) \quad \text { for all } n \text {. }
$$

Further set $x_{0}=x, y_{0}=y, z_{0}=z$ and $t_{0}=t$, in a similar way, define the sequences $\left\{g x_{n}\right\}$, $\left\{g y_{n}\right\}$ and $\left\{g z_{n}\right\},\left\{g t_{n}\right\}$. Then it is easy to show that

$$
g x_{n} \rightarrow F(x, y), \quad g y_{n} \rightarrow F(y, x) \quad \text { and } \quad g z_{n} \rightarrow F(z, t), \quad g t_{n} \rightarrow F(t, z)
$$

as $n \rightarrow \infty$. Since

$$
(F(x, y), F(y, x))=\left(g x_{1}, g y_{1}\right)=(g x, g y) \quad \text { and } \quad(F(u, v), F(v, u))=\left(g u_{1}, g v_{1}\right)
$$

are comparable, then $g x \leq g u_{1}$ and $g y \geq g v_{1}$, or vice versa. It is easy to show that, similarly, $(g x, g y)$ and $\left(g u_{n}, g v_{n}\right)$ are comparable for all $n \geq 1$, that is, $g x \leq g u_{n}$ and $g y \geq g v_{n}$, or vice versa. Thus from (2.1), we have

$$
\begin{aligned}
\varphi\left(d\left(g x, g u_{n+1}\right)\right) & =\varphi\left(F(x, y), F\left(u_{n}, v_{n}\right)\right) \\
& \leq \frac{1}{2} \varphi\left(d\left(g x, g u_{n}\right)+d\left(g y, g v_{n}\right)\right)-\psi\left(\frac{d\left(g x, g u_{n}\right)+d\left(g y, g v_{n}\right)}{2}\right) .
\end{aligned}
$$


Similarly,

$$
\begin{aligned}
\varphi\left(d\left(g v_{n+1}, g y\right)\right) & =\varphi\left(F\left(v_{n}, u_{n}\right), F(y, x)\right) \\
& \leq \frac{1}{2} \varphi\left(d\left(g v_{n}, g y\right)+d\left(g u_{n}, g x\right)\right)-\psi\left(\frac{d\left(g v_{n}, g y\right)+d\left(g u_{n}, g x\right)}{2}\right) .
\end{aligned}
$$

From (2.16), (2.17) and the property of $\varphi$, we have

$$
\begin{aligned}
& \varphi\left(d\left(g x, g u_{n+1}\right)+d\left(g v_{n+1}, g y\right)\right) \\
& \quad \leq \varphi\left(d\left(g x, g u_{n+1}\right)\right)+\varphi\left(d\left(g v_{n+1}, g y\right)\right) \\
& \quad \leq \varphi\left(d\left(g x, g u_{n}\right)+d\left(g y, g v_{n}\right)\right)-2 \psi\left(\frac{d\left(g x, g u_{n}\right)+d\left(g y, g v_{n}\right)}{2}\right)
\end{aligned}
$$

which implies

$$
\varphi\left(d\left(g x, g u_{n+1}\right)+d\left(g v_{n+1}, g y\right)\right) \leq \varphi\left(d\left(g x, g u_{n}\right)+d\left(g y, g v_{n}\right)\right) .
$$

Thus,

$$
d\left(g x, g u_{n+1}\right)+d\left(g v_{n+1}, g y\right) \leq d\left(g x, g u_{n}\right)+d\left(g y, g v_{n}\right) .
$$

That is, the sequence $\left\{d\left(g x, g u_{n}\right)+d\left(g y, g v_{n}\right)\right\}$ is decreasing. Therefore, there exists $\alpha \geq 0$ such that

$$
\lim _{n \rightarrow \infty}\left[d\left(g x, g u_{n}\right)+d\left(g y, g v_{n}\right)\right]=\alpha .
$$

We shall show that $\alpha=0$. Suppose, to the contrary, that $\alpha>0$. Taking the limit as $n \rightarrow \infty$ in (2.18), we have

$$
\varphi(\alpha) \leq \varphi(\alpha)-2 \lim _{n \rightarrow \infty} \psi\left(\frac{d\left(g x, g u_{n}\right)+d\left(g y, g v_{n}\right)}{2}\right)<\varphi(\alpha),
$$

a contradiction. Thus, $\alpha=0$, that is,

$$
\lim _{n \rightarrow \infty}\left[d\left(g x, g u_{n}\right)+d\left(g y, g v_{n}\right)\right]=0 .
$$

It implies

$$
\lim _{n \rightarrow \infty} d\left(g x, g u_{n}\right)=\lim _{n \rightarrow \infty} d\left(g y, g v_{n}\right)=0 .
$$

Similarly, we show that

$$
\lim _{n \rightarrow \infty} d\left(g z, g u_{n}\right)=\lim _{n \rightarrow \infty} d\left(g t, g v_{n}\right)=0 .
$$

From (2.19), (2.20) and by the uniqueness of the limit, it follows that we have $g x=g z$ and $g y=g t$. Hence $(g x, g y)$ is the unique coupled point of coincidence of $F$ and $g$. 
Example 1 Let $X=[0,+\infty)$ endowed with the standard metric $d(x, y)=|x-y|$ for all $x, y \in X$. Then $(X, d)$ is a complete metric space. Define the mapping $F: X \times X \rightarrow X$ by

$$
F(x, y)= \begin{cases}y & \text { if } x \geq y \\ x & \text { if } x<y\end{cases}
$$

Suppose that $g: X \rightarrow X$ is such that $g x=x^{2}$ for all $x \in X$ and $\varphi(t):[0,+\infty) \rightarrow[0,+\infty)$ is such that $\varphi(t)=t$. Assume that $\psi(t)=\frac{t}{1+t}$.

It is easy to show that for all $x, y, u, v \in X$ with $g x \leq g u$ and $g y \geq g \nu$, we have

$$
\varphi(d(F(x, y), F(u, v))) \leq \frac{1}{2} \varphi(d(g x, g u)+d(g y, g v))-\psi\left(\frac{d(g x, g u)+d(g y, g v)}{2}\right) .
$$

Thus, it satisfies all the conditions of Theorem 4. So we deduce that $F$ and $g$ have a coupled coincidence point $(x, y) \in X \times X$. Here, $(0,0)$ is a coupled coincidence point of $F$ and $g$.

\section{Competing interests}

The authors declare that they have no competing interests.

\section{Authors' contributions}

Both authors contributed equally and significantly in writing this paper. Both authors read and approved the final manuscript.

\section{Author details}

${ }^{1}$ Department of Mathematics, Faculty of Science, University of Gazi, Teknikokullar, Ankara, 06500, Turkey. ${ }^{2}$ Department of Mathematics, Faculty of Science and Arts, University of Amasya, Amasya, 05100, Turkey. ${ }^{3}$ Department of Mathematics, Faculty of Science and Arts, University of Giresun, Gazipaşa, Giresun, Turkey.

Received: 11 June 2013 Accepted: 1 December 2013 Published: 20 Dec 2013

\section{References}

1. Banach, S: Sur les opérations dans les ensembles abstraits et leur application aux équations intégrales. Fundam Math. 3, 133-181 (1922)

2. Ran, ACM, Reurings, MCB: A fixed point theorem in partially ordered sets and some applications to matrix equations. Proc. Am. Math. Soc. 132, 1435-1443 (2004)

3. Altun, I, Simsek, H: Some fixed point theorems on ordered metric spaces and application. Fixed Point Theory Appl. 2010, Article ID 621469 (2010)

4. Bhaskar, TG, Lakshmikantham, V: Fixed point theorems in partially ordered metric spaces and applications. Nonlinear Anal. 65, 1379-1393 (2006)

5. Harjani, J, Sadarangani, K: Generalized contractions in partially ordered metric spaces and applications to ordinary differential equations. Nonlinear Anal. TMA 72, 1188-1197 (2010)

6. Nieto, JJ, Rodriquez-Lopez, R: Contractive mapping theorems in partially ordered sets and applications to ordinary differential equation. Order 22, 223-239 (2005)

7. Nieto, JJ, Rodriquez-Lopez, R: Existence and uniqueness of fixed point in partially ordered sets and applications to ordinary differential equations. Acta Math. Sin. Engl. Ser. 23(12), 2205-2212 (2007)

8. Lakshmikantham, V, Ćirić, LB: Coupled fixed point theorems for nonlinear contractions in partially ordered metric spaces. Nonlinear Anal. (2008). doi:10.1016/j.na.2008.09.020

9. Agarwal, RP, El-Gebeily, MA, O'Regan, D: Generalized contractions in partially ordered metric spaces. Appl. Anal. 87 1-8 (2008)

10. Samet, B: Coupled fixed point theorems for a generalized Meir-Keeler contraction in partially ordered metric spaces Nonlinear Anal. TMA (2010). doi:10.1016/j.na.2010.02.026

11. Aydi, H, Karapınar, E, Shatanawi, W: Coupled fixed point results for $(\psi-\varphi)$-weakly contractive condition in ordered partial metric spaces. Comput. Math. Appl. 62, 4449-4460 (2011)

12. Choudhury, BS, Kundu, A: A coupled coincidence point result in partially ordered metric spaces for compatible mappings. Nonlinear Anal. 73, 2524-2531 (2010)

13. Samet, B: Coupled fixed point theorems for a generalized Meir-Keeler contraction in partially ordered metric spaces. Nonlinear Anal. 72, 4508-4517 (2010)

14. Nashine, HK, Kadelburg, Z, Radenović, S: Coupled common fixed point theorems for $\omega^{*}$-compatible mappings in ordered cone metric spaces. Appl. Math. Comput. 218, 5422-5432 (2012)

15. Radenović, S, Kadelburg, Z: Generalized weak contractions in partially ordered metric spaces. Comput. Math. Appl. 60, 1776-1783 (2010)

16. Abbas, M, Sintunavarat, W, Kumam, P: Coupled fixed point of generalized contractive mappings on partially ordered G-metric spaces. Fixed Point Theory Appl. 2012, 31 (2012) 
17. Sintunavarat, W, Cho, YJ, Kumam, P: Coupled fixed point theorems for weak contraction mapping under F-invariant set. Abstr. Appl. Anal. 2012, Article ID 324874 (2012)

18. Sintunavarat, W, Kumam, P: Coupled best proximity point theorem in metric spaces. Fixed Point Theory Appl. 2012, $93(2012)$

19. Sintunavarat, W, Kumam, P: Coupled coincidence and coupled common fixed point theorems in partially ordered metric spaces. Thai J. Math. (2012, in press)

20. Sintunavarat, W, Cho, YJ, Kumam, P: Coupled fixed point theorems for contraction mapping induced by cone ball-metric in partially ordered spaces. Fixed Point Theory Appl. 2012, 128 (2012)

21. Sintunavarat, W, Petrusel, A, Kumam, P: Common coupled fixed point theorems for $w$-compatible mappings without mixed monotone property. Rend. Circ. Mat. Palermo 61, 361-383 (2012)

22. Sintunavarat, W, Kumam, P, Cho, YJ: Coupled fixed point theorems for nonlinear contractions without mixed monotone property. Fixed Point Theory Appl. 2012, 170 (2012)

23. Karapınar, E, Kumam, P, Sintunavarat, W: Coupled fixed point theorems in cone metric spaces with a c-distance and applications. Fixed Point Theory Appl. 2012, 194 (2012)

24. Sintunavarat, W, Radenović, S, Golubović, Z, Kumam, P: Coupled fixed point theorems for F-invariant set. Appl. Math. Inform. Sci. 7(1), 247-255 (2013)

25. Sintunavarat, W, Cho, YJ, Kumam, P: Coupled coincidence point theorems for contractions without commutative condition in intuitionistic fuzzy normed spaces. Fixed Point Theory Appl. 2011, 81 (2011)

26. Berinde, $\mathrm{V}$ : Generalized coupled fixed point theorems for mixed monotone mappings in partially ordered metric spaces. Nonlinear Anal. 74, 7347-7355 (2011)

27. Nashine, HK, Shatanawi, W: Coupled common fixed point theorems for pair of commuting mappings in partially ordered complete metric spaces. Comput. Math. Appl. 62, 1984-1993 (2011)

28. Haghi, RH, Rezapour, S, Shahzad, N: Some fixed point generalizations are not real generalizations. Nonlinear Anal. 74, 1799-1803 (2011). doi:10.1016/j.na.2010.10.052

29. Luong, NV, Thuan, NX: Coupled fixed points in partially ordered metric spaces and application. Nonlinear Anal. 74 983-992 (2011)

10.1186/1687-1812-2013-348

Cite this article as: Turkoglu and Sangurlu: Coupled fixed point theorems for mixed $g$-monotone mappings in partially ordered metric spaces. Fixed Point Theory and Applications 2013, 2013:348

\section{Submit your manuscript to a SpringerOpen ${ }^{0}$ journal and benefit from:}

- Convenient online submission

- Rigorous peer review

- Immediate publication on acceptance

- Open access: articles freely available online

- High visibility within the field

- Retaining the copyright to your article 